\title{
Effect of inhibitors of polyamine synthesis on activation of diapausing mouse blastocysts in vitro
}

\author{
L. J. Van Winkle and A. L. Campione \\ Department of Biochemistry, Chicago College of Osteopathic Medicine, 1122 East 53rd Street, \\ Chicago, Illinois 60615, U.S.A.
}

\begin{abstract}
Summary. Diapausing mouse blastocysts were cultured in vitro with inhibitors of polyamine synthesis and/or the polyamines, putrescine, spermidine and/or spermine. Attachment of blastocysts to the culture dish, the onset of trophoblastic outgrowth and the extent of outgrowth were retarded by methylornithine $(10 \mathrm{~mm})$ or methylglyoxal bis(guanylhydrazone) ( 50 or $200 \mu \mathrm{M})$ and apparently blocked by a combination of these inhibitors. The embryos appeared to make no progress towards activation in the presence of both inhibitors but became active and grew normally when transferred to inhibitor-free medium. The inhibition of growth was also reversed when polyamines $\left(10^{-5} \mathrm{M}\right)$ were supplied in the medium along with the inhibitors $(P<0.01)$. These results suggest that polyamine synthesis is required for activation, growth and development of diapausing blastocysts in vitro.
\end{abstract}

\section{Introduction}

Blastocysts enter a state of apparent quiescence, termed diapause, in which they fail to attach to the uterus, when mated mice are ovariectomized $1 \frac{1}{2}=$ days before implantation would have occurred (McLaren, 1973; Sherman \& Wudl, 1976). These embryos appear to become metabolically active, attach to the culture dish and continue to grow when they are cultured in medium containing essential amino acids, glucose and fetal calf serum (Gwatkin, 1966; McLaren, 1973; Spindle \& Pedersen, 1973; Sherman \& Wudl, 1976; Van Blerkom, Chavez \& Bell, 1979; Naeslund, 1979). In contrast, activation in vitro apparently does not occur when the medium contains a low ( $55 \mathrm{~mm}$ ) concentration of $\mathrm{Na}^{+}$, possibly because accumulation of essential amino acids is depressed in blastocysts cultured in such conditions (Van Winkle, 1977, 1981a). Low $\mathrm{Na}^{+}$may also help to produce apparent diapause by limiting the activity of ornithine decarboxylase. Sodium is required for stimulation of ornithine decarboxylase activity in neuroblastoma cells (Viceps-Madore, Chen, Tsou \& Canellakis, 1982). An increase in ornithine decarboxylase activity may accompany activation and growth of blastocysts because this enzyme controls production of polyamines which are required for DNA, and possibly RNA and protein, synthesis and thus for cell proliferation in other systems (Heby, 1981).

Ornithine decarboxylase catalyses the conversion of ornithine to putrescine (Text-fig. 1) (Williams-Ashman \& Canellakis, 1979; Heby, 1981). Another rate-controlling enzyme in polyamine synthesis, S-adenosylmethionine decarboxylase, catalyses the decarboxylation of Sadenosylmethionine (Heby, 1981). Decarboxylated S-adenosylmethionine reacts with putrescine to produce spermidine and with spermidine to generate spermine (Text-fig. 1). Inhibitors of these two rate-controlling enzymes in polyamine synthesis have been helpful in demonstrating that the polyamines, putrescine, spermidine and spermine, are required universally for cell proliferation 
(Heby, 1981). Diapausing blastocysts may have naturally low concentrations of polyamines because their cells are arrested in $G_{1}$ of the cell cycle (Sherman \& Barlow, 1972) and several types of cells are arrested in $G_{1}$ when cultured in vitro in the presence of inhibitors of polyamine synthesis (Sunkara \& Rao, 1981; Seidenfeld, Gray \& Marton, 1981).

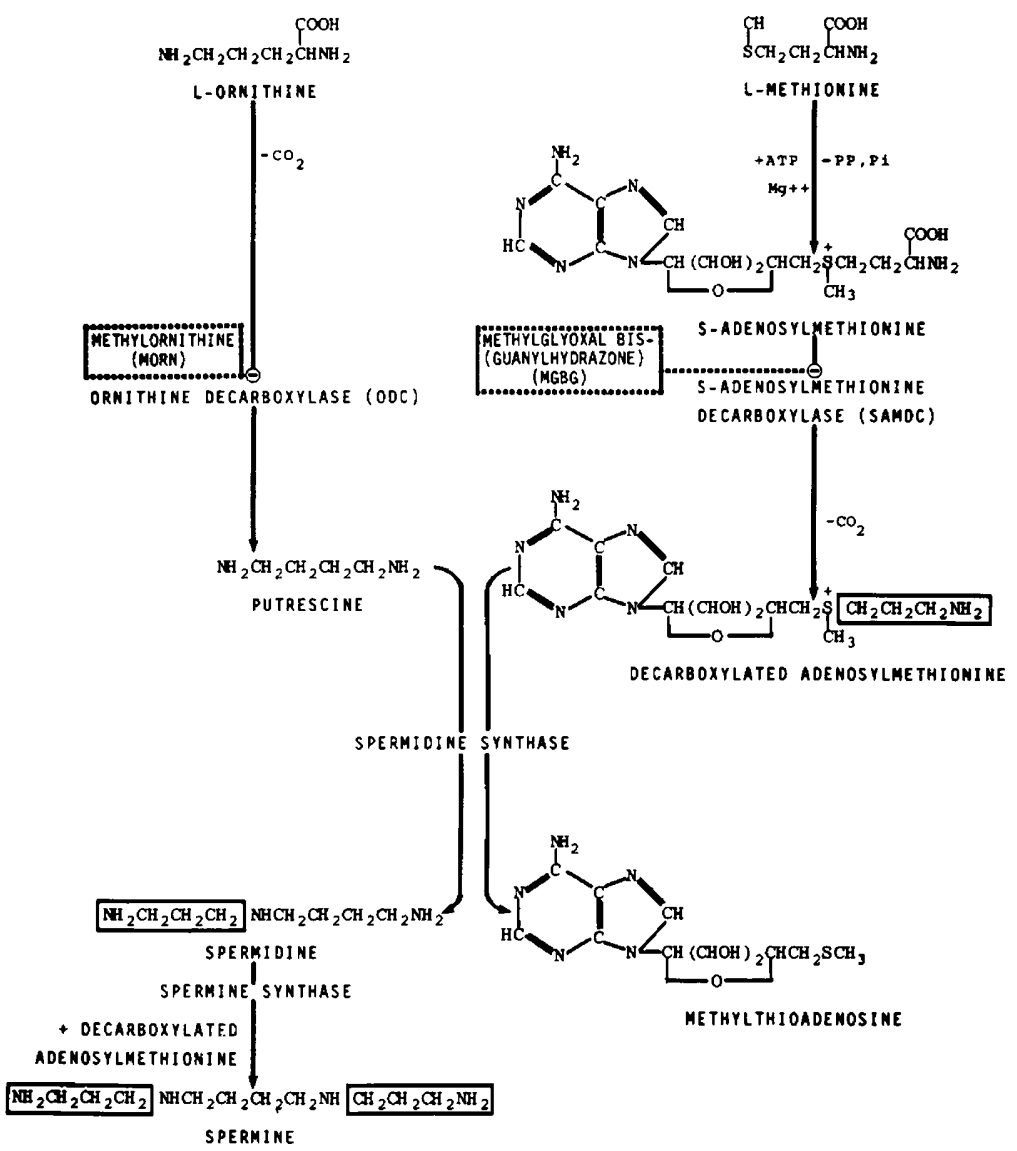

Text-fig. 1. Biosynthesis of putrescine, spermidine and spermine (adapted from Tabor \& Tabor, 1976).

The purpose of this study was to examine the effects of the ornithine decarboxylase inhibitor, methylornithine, and the S-adenosylmethionine decarboxylase inhibitor, methylglyoxal bis(guanylhydrazone) (MGBG), on growth of diapausing blastocysts cultured in vitro. We also determined whether an exogenous supply of polyamines was beneficial to embryos incubated with inhibitors of polyamine synthesis.

\section{Materials and Methods}

Swiss, ICR mice (Harlan, Sprague-Dawley, Inc.), which had been induced to ovulate and mate, were subsequently ovariectomized before $12: 00 \mathrm{~h}$ on the 4 th day post coitum (p.c.) as previously described (Fowler \& Edwards, 1957; Van Winkle, 1977). The day of detection of a copulatory plug was designated Day 1 p.c. 
Diapausing blastocysts were flushed from excised uteri of ovariectomized mice (killed by cervical dislocation) on Days 8-13 p.c. with Dulbecco's modified Eagle medium (Gibco, Grand Island, N.Y.) supplemented with $100 \mathrm{U}$ penicillin $\mathrm{G} / \mathrm{ml}$ and $50 \mu \mathrm{g}$ streptomycin sulphate $/ \mathrm{ml}$ (MEM) as described previously (Van Winkle, 1977, 1981a, b). The medium also contained $10 \%$ fetal calf serum (FCS; Gibco) or 10\% dialysed FCS (Gibco). Groups of 10-35 embryos were washed then cultured in the depression of a Maximov slide containing 1-2 ml fresh medium (Van Winkle, 1981a, b; Van Winkle \& Campione, 1982). In some cases, the medium also contained methylornithine (Calbiochem, San Diego, California), methylglyoxal bis-(guanylhydrazone) (Sigma Chemical Company, St Louis, Missouri), putrescine (Sigma), spermidine (Sigma) and/or spermine (Sigma) at concentrations indicated in the text or tables. Cultured embryos were examined periodically with a dissecting microscope for the onset of trophoblastic outgrowth. In some cases, the sizes of the outgrowths were estimated by measuring the diameter of 5 representative outgrowths in each culture. Experiments were repeated three or more times as indicated in the tables. The experiments reported in Text-fig. 2 were repeated twice. Data from replicate experiments were combined since the results were similar each time a treatment was used. Factors which are difficult to control, such as different batches of FCS and dialysed FCS, can cause the time before onset of outgrowth to vary in experiments performed at different times. Therefore, the effects of treatments on embryos were always compared to control embryos which were selected from the same original common pool of embryos and grown at the same time using the same culture materials as embryos exposed to inhibitors and/or polyamines (within table comparison). Direct comparison of data in different tables in this study is not valid. The fractions of embryos which had formed trophoblastic outgrowths under the various culture conditions were compared statistically with two-by-two contingency tables (Woolf, 1968). When more than two groups were compared, this statistical test was applied only to adjacent groups to avoid Type 1 errors similar to those produced when other than neighbouring groups are compared with Student's $t$ test (Woolf, 1968). The mean diameters of outgrowths that formed after various treatments were compared by analysis of variance coupled with a multiple range test (Kramer, 1956; Woolf, 1968).

Table 1. Effect of inhibitors of polyamine synthesis on formation of trophoblastic outgrowths by delayed implantation blastocysts cultured in vitro

\begin{tabular}{|c|c|c|c|c|}
\hline \multirow{2}{*}{$\begin{array}{l}\text { Inhibitor added } \\
\text { to medium** }\end{array}$} & \multirow{2}{*}{$\begin{array}{l}\text { No. of } \\
\text { embryos cultured }\end{array}$} & \multicolumn{3}{|c|}{ No. $(\%)$ of blastocysts forming outgrowths } \\
\hline & & $1 \frac{3}{4}$ days & 2 days & 3 days \\
\hline None $^{e}$ & 150 & $28(18 \cdot 7)$ & $74(49 \cdot 3)$ & $122(81 \cdot 3)$ \\
\hline MORN $(10 \mathrm{~mm})^{\mathrm{b}}$ & 100 & $1(1 \cdot 0)$ & $6(6 \cdot 0)$ & $11(11 \cdot 0)$ \\
\hline MORN $(2.5 \mathrm{~mm})^{e}$ & 106 & $14(13 \cdot 2)$ & $57(53.8)$ & $78(73 \cdot 6)$ \\
\hline MGBG $(200 \mu \mathrm{M})^{\mathrm{d}}$ & 79 & $8(10 \cdot 1)$ & $26(32.9)$ & $30(38.0)$ \\
\hline MGBG $(50 \mu \mathrm{M})^{\mathrm{d}}$ & 109 & $8(7 \cdot 3)$ & $26(23.9)$ & $39(35.8)$ \\
\hline $\begin{array}{l}\text { MORN }(10 \mathrm{mM}) \\
\quad+\text { MGBG }(200 \mu \mathrm{M})^{\mathrm{a}}\end{array}$ & 72 & $0(0.0)$ & $0(0 \cdot 0)$ & $0(0 \cdot 0)$ \\
\hline $\begin{array}{l}\text { MORN }(10 \mathrm{mM}) \\
\quad+\text { MGBG }(50 \mu \mathrm{M})^{\mathrm{a}}\end{array}$ & 70 & $0(0 \cdot 0)$ & $1(1 \cdot 4)$ & $1(1 \cdot 4)$ \\
\hline $\begin{array}{l}\text { MORN }(2.5 \mathrm{mM}) \\
\quad+\text { MGBG }(200 \mu \mathrm{M})^{\mathrm{a}}\end{array}$ & 109 & $2(1 \cdot 8)$ & $2(1 \cdot 8)$ & $3(2 \cdot 8)$ \\
\hline $\begin{array}{l}\text { MORN }(2.5 \mathrm{mM}) \\
\quad+\text { MGBG }(50 \mu \mathrm{M})^{\mathrm{c}}\end{array}$ & 114 & $5(4 \cdot 4)$ & $10(8 \cdot 8)$ & $31(27 \cdot 2)$ \\
\hline
\end{tabular}

MORN, methylornithine; MGBG, methylglyoxal bis-(guanylhydrazone). Medium was Dulbecco's modified Eagle medium $+10 \%$ fetal calf serum.

* Groups with different superscripts are significantly different $(P<0.025)$ when adjacent groups are compared with two-by-two contingency tables at one or all of the indicated times in culture. Six or more independent experiments were performed for each group and the resultant data were pooled because the trends were the same in each experiment. 


\section{Results}

The onset of trophoblastic outgrowths was inhibited by $10 \mathrm{mM}$-methylornithine or MGBG (50 or $200 \mu \mathrm{M}$ ) and completely blocked by a combination of $10 \mathrm{mM}$-methylornithine and $200 \mu \mathrm{M}-\mathrm{MGBG}$ (Table 1). In the latter case, $94 \%$ of the blastocysts also did not attach to the culture dish. Lower concentrations of MGBG (e.g. $20 \mu \mathrm{M}$ ) had no consistent inhibitory effect on the onset of outgrowth (data not shown). To see whether activation and further growth of diapausing blastocysts would resume when the inhibitors were removed, blastocysts in some of the experiments reported in Table 1 were washed twice ( $>100: 1$ dilution per wash) and transferred to fresh, inhibitor-free medium after 3 days of incubation with these inhibitors. The latter blastocysts apparently had made no progress towards the formation of trophoblastic outgrowths for they required as much time to form outgrowths after transfer from medium which contained inhibitors as did diapausing embryos in control culture (Text-fig. 2). Apart from apparent inhibition of their activation, blastocysts incubated with inhibitors of polyamine synthesis and the trophoblastic outgrowths they formed after transfer to inhibitor-free medium did not appear to be adversely affected.

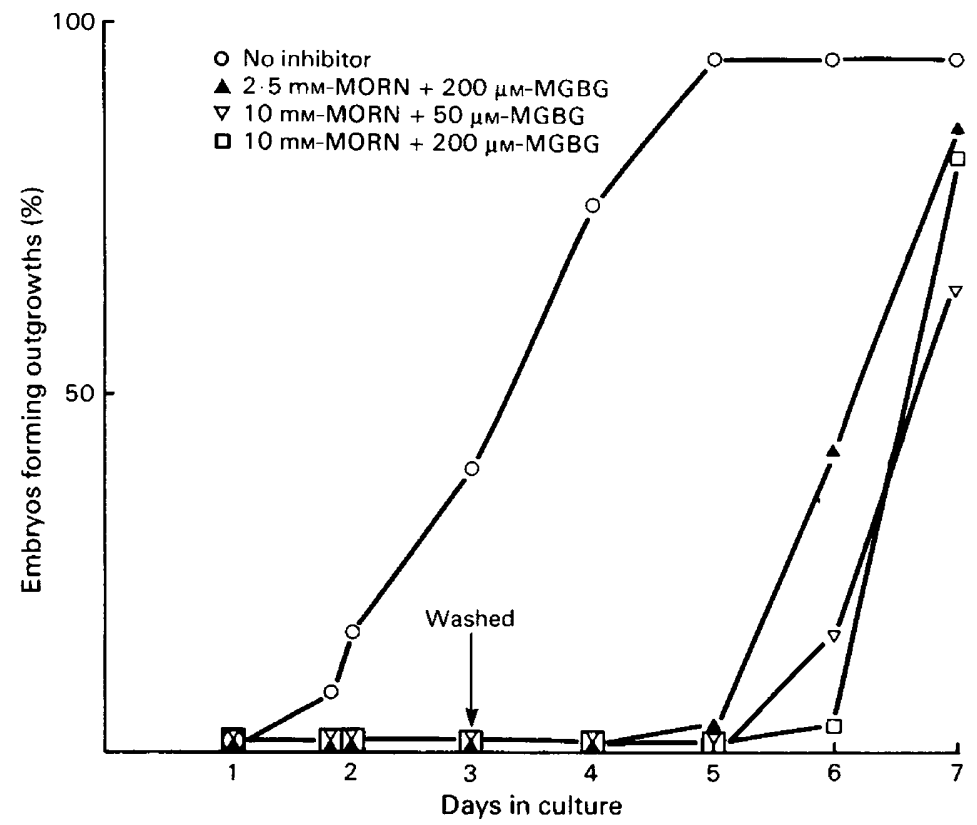

Text-fig. 2. The effect of washing on growth and development of diapausing rat blastocysts cultured in vitro with inhibitors of polyamine synthesis. Blastocysts in two replicate experiments were cultured with methylornithine (MORN) plus MGBG for 3 days then washed (twice; >100:1 dilution per wash) and cultured in MEM + FCS containing no inhibitors. Data up to Day 3 of culture were pooled with other data and reported in Table 1.

Inhibition of the onset of trophoblastic outgrowth by methylornithine plus MGBG was partly reversed by putrescine, spermidine and spermine $\left(10^{-5} \mathrm{M}\right.$ each) but these concentrations of polyamines were also apparently toxic, as evidenced by collapse of some blastocysts which did not attach to the culture dish or grow (Table 2). Polyamines were less toxic to blastocysts when the medium contained dialysed FCS (Table 3) instead of FCS (Table 2), however, $10^{-4} \mathrm{M}$-polyamines were toxic in dialysed FCS regardless of the presence of inhibitors of polyamine synthesis (data not shown). We were therefore unable to determine whether inhibition of growth by MGBG plus methylornithine could be completely reversed by supplying higher concentrations of exogenous polyamines in the culture medium. Similarly, spermine and spermidine $\left(10^{-5} \mathrm{M}\right)$ partly reversed 
Table 2. Effect of spermine, spermidine and putrescine (PAs) on the inhibition of trophoblastic outgrowth by inhibitors of PA synthesis in MEM + FCS (pooled data from 3 experiments)

\begin{tabular}{|c|c|c|c|c|}
\hline \multirow{2}{*}{$\begin{array}{l}\text { Addition to } \\
\text { medium }\end{array}$} & \multirow{2}{*}{$\begin{array}{l}\text { No. of } \\
\text { embryos cultured }\end{array}$} & \multicolumn{3}{|c|}{ No. $(\%)$ of blastocysts forming outgrowths } \\
\hline & & 2 days & 3 days & 4 days \\
\hline None & 59 & $25(42 \cdot 4)$ & $47(79 \cdot 7)$ & $57(96 \cdot 6)$ \\
\hline PAs $\left(10^{-5}\right.$ M each $)$ & $73 \dagger$ & - & $\ldots$ & - \\
\hline $\begin{array}{l}\text { MORN }(2.5 \mathrm{mM}) \\
\quad+\text { MGBG }(200 \mu \mathrm{M})\end{array}$ & 59 & $1(1 \cdot 7)$ & $6(10 \cdot 2)$ & $15(25 \cdot 4)$ \\
\hline $\begin{array}{l}\text { MORN }(2.5 \mathrm{mM}) \\
\quad+\text { MGBG }(200 \mu \mathrm{M}) \\
+ \text { PAs }\left(10^{-5} \mathrm{M} \text { each }\right)\end{array}$ & 59 & $0(0 \cdot 0)$ & $6(10 \cdot 2)$ & $17(28 \cdot 8)$ \\
\hline $\begin{array}{l}\text { MORN }(10 \mathrm{mM}) \\
\quad+\mathrm{MGBG}(50 \mu \mathrm{M})\end{array}$ & 60 & $2(3 \cdot 3)$ & $5(8 \cdot 3)$ & $9(15 \cdot 0)\}$ \\
\hline $\begin{array}{l}\text { MORN }(10 \mathrm{mM}) \\
\quad+\text { MGBG }(50 \mu \mathrm{M}) \\
\quad+\text { PAs }\left(10^{-5} \mathrm{M} \text { each }\right)\end{array}$ & 59 & $3(5 \cdot 1)$ & $20(33.9)\}$ & $39(66 \cdot 1) J$ \\
\hline $\begin{array}{l}\text { MORN }(2.5 \mathrm{~mm}) \\
+\mathrm{MGBG}(50 \mu \mathrm{M})\end{array}$ & 60 & $4(6 \cdot 7)$ & $12(20 \cdot 0)$ & $23(38 \cdot 3)$ \\
\hline $\begin{array}{l}\text { MORN }(2.5 \mathrm{mM}) \\
\quad+\text { MGBG }(50 \mu \mathrm{M}) \\
\quad+\text { PAs }\left(10^{-5} \mathrm{M} \text { each }\right)\end{array}$ & $60 \ddagger$ & $12(20 \cdot 0) J$ & $25(41 \cdot 7) J$ & $33(55 \cdot 0)$ \\
\hline
\end{tabular}

MEM, Dulbecco's modified Eagle medium; FCS, fetal calf serum; PAs, polyamines; MORN, methylornithine; MGBG, methylglyoxal bis-(guanylhydrazone).

$\dagger 42$ embryos appeared to be dead after $24 \mathrm{~h}$ in culture.

$\$ 22$ embryos appeared to be dead after $24 \mathrm{~h}$ in culture.

$* P<0.05$.

** $P<0.01$.

Table 3. Effect of spermine, spermidine and putrescine (PAs) on the inhibition of trophoblastic outgrowth by inhibitors of PA synthesis in MEM + dialysed FCS (pooled data from 4 experiments)

\begin{tabular}{|c|c|c|c|c|}
\hline \multirow{2}{*}{$\begin{array}{l}\text { Addition to } \\
\text { medium }\end{array}$} & \multirow{2}{*}{$\begin{array}{l}\text { No. of } \\
\text { embryos cultured }\end{array}$} & \multicolumn{3}{|c|}{ No. $(\%)$ of blastocysts forming outgrowths } \\
\hline & & 2 days & 3 days & 4 days \\
\hline None & 93 & $40(43 \cdot 0)\}$ & $86(92.5)\}$ & $92(98 \cdot 9)\}$ \\
\hline PAs $\left(10^{-5}\right.$ M each $)$ & 95 & $11(11 \cdot 6)\}$ & $52(54 \cdot 7)\}$ & $68(71 \cdot 6)\}$ \\
\hline $\begin{array}{l}\text { MORN }(2.5 \mathrm{mM}) \\
\quad+\text { MGBG }(200 \mu \mathrm{M})\end{array}$ & 108 & $1(0 \cdot 9)$ & $8(7 \cdot 4)$ & $17(15 \cdot 7)$ \\
\hline $\begin{array}{l}\text { MORN }(2.5 \mathrm{mM}) \\
\quad+\text { MGBG }(200 \mu \mathrm{M}) \\
\quad+\text { PAs }\left(10^{-5} \mathrm{M} \mathrm{each}\right)\end{array}$ & 110 & $5(4 \cdot 5)$ & $22(20 \cdot 0) \mathrm{J}$ & $54(49 \cdot 1) J$ \\
\hline $\begin{array}{l}\text { MORN }(10 \mathrm{mM}) \\
\quad+\text { MGBG }(50 \mu \mathrm{M})\end{array}$ & 106 & $8(7 \cdot 5)$ & $16(15 \cdot 1)$ & $\dagger 17(20 \cdot 4)$ \\
\hline $\begin{array}{l}\text { MORN }(10 \mathrm{mM}) \\
\quad+\text { MGBG }(50 \mu \mathrm{M}) \\
\quad+\text { PAs }\left(10^{-5} \mathrm{M} \text { each }\right)\end{array}$ & 107 & $6(5 \cdot 6)$ & $32(29 \cdot 9) J$ & $\dagger 47(56 \cdot 0) J$ \\
\hline $\begin{array}{l}\text { MORN }(2.5 \mathrm{mM}) \\
\quad+\text { MGBG }(50 \mu \mathrm{M})\end{array}$ & 107 & $10(9 \cdot 3)$ & $23(21 \cdot 5)$ & $37(34 \cdot 6)$ \\
\hline $\begin{array}{l}\text { MORN }(2.5 \mathrm{mM}) \\
\quad+\text { MGBG }(50 \mu \mathrm{M}) \\
\quad+\text { PAs }\left(10^{-5} \mathrm{M} \text { each }\right)\end{array}$ & 100 & $7(7 \cdot 0)$ & $34(34 \cdot 0) J$ & $63(63 \cdot 0))$ \\
\hline
\end{tabular}

MEM, Dulbecco's modified Eagle medium; PAs, polyamines; MORN, methylornithine; MGBG, methylglyoxal bis-(guanylhydrazone).

† One experiment was not recorded at this time for these groups.

$* P<0.05$.

** $P<0.01$. 
Table 4. Effect of spermine and spermidine (PAs) on inhibition of trophoblastic outgrowth by MGBG in MEM + dialysed FCS (pooled data from $\geqslant 4$ experiments)

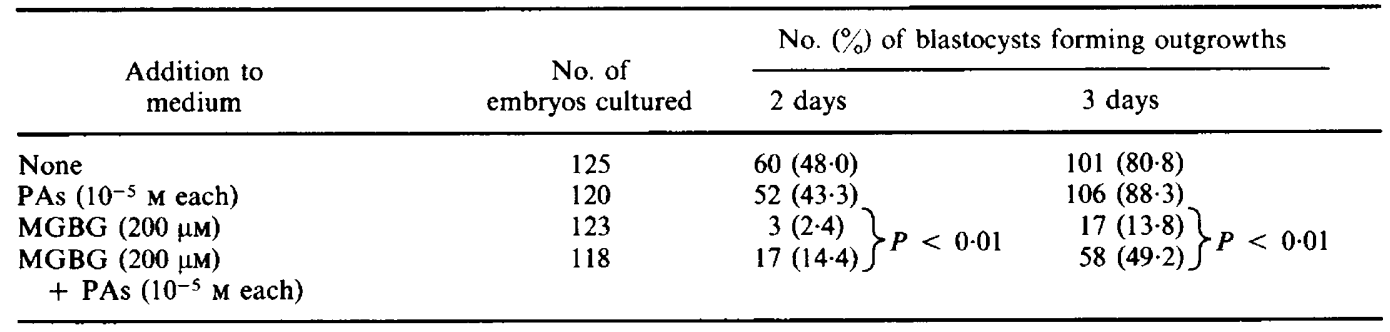

PAs, polyamines; MGBG, methylglyoxal bis-(guanylhydrazone); MEM, Dulbecco's modified Eagle medium.

inhibition by MGBG (Table 4) but higher concentrations of these polyamines were toxic (data not shown). Lower concentrations of putrescine, spermine and spermidine (i.e. $10^{-6}$ or $10^{-8} \mathrm{M}$ each) also partly reversed the effects of MGBG plus methylornithine ( $P<0.01$; data not shown).

Complete reversal of inhibition by methylornithine was achieved with putrescine which was not toxic even at a concentration of $10^{-3} \mathrm{M}$ (Table 5). Putrescine also stimulated the onset of outgrowth by blastocysts in the absence of methylornithine. However, while putrescine increased the size of trophoblastic outgrowths that formed in the presence of methylornithine (Table 5), it had no statistically significant effect on the size of outgrowths in the absence of methylornithine (data not shown).

Table 5. Effect of putrescine on methylornithine-inhibited trophoblastic outgrowth of delayed implantation blastocysts in MEM + dialysed FCS (pooled data from 3 experiments)

\begin{tabular}{|c|c|c|c|}
\hline $\begin{array}{l}\text { Addition to } \\
\text { medium }\end{array}$ & $\begin{array}{l}\text { No. of } \\
\text { embryos cultured }\end{array}$ & $\begin{array}{l}\text { No. }(\%)^{*} \text { of embryos } \\
\text { forming outgrowths after } \\
3 \text { days in culture }\end{array}$ & $\begin{array}{c}\text { Mean } \pm \text { s.e.m. diam. }(\mu \mathrm{m}) \\
\text { of outgrowths** }\end{array}$ \\
\hline None & 66 & $50(75 \cdot 8)^{a}$ & $325 \pm 17^{a}$ \\
\hline MORN $10 \mathrm{mM}$ ) & 68 & $35(51 \cdot 5)^{b}$ & $233 \pm 17^{b}$ \\
\hline $\begin{array}{l}\text { MORN }(10 \mathrm{~mm}) \\
\quad+\text { putrescine }\left(10^{-6} \mathrm{M}\right)\end{array}$ & 66 & $35(53 \cdot 0)^{\mathrm{b}}$ & $233 \pm 21^{b}$ \\
\hline $\begin{array}{l}\text { MORN (10 mM) } \\
\quad+\text { putrescine }\left(10^{-5} \mathrm{M}\right)\end{array}$ & 68 & $39(57 \cdot 4)^{\mathrm{b}}$ & $271 \pm 17^{a . b}$ \\
\hline $\begin{array}{l}\text { MORN }(10 \mathrm{~mm}) \\
\quad+\text { putrescine }\left(10^{-4} \mathrm{M}\right)\end{array}$ & 66 & $35(53 \cdot 0)^{\mathrm{a}}$ & $262 \pm 18^{a . b}$ \\
\hline $\begin{array}{l}\text { MORN (10 mM) } \\
\quad+\text { putrescine }\left(10^{-3} \mathrm{M}\right)\end{array}$ & 69 & $50(72 \cdot 5)^{\mathrm{a}}$ & $317 \pm 17^{a}$ \\
\hline
\end{tabular}

MORN, methylornithine; MEM, Dulbecco's modified Eagle medium.

* Groups with different superscripts are significantly different $(P<0.05)$.

** Groups with different superscripts are significantly different $(P<0.01)$.

\section{Discussion}

It appears that at least one of the primary effects of methylornithine and MGBG on diapausing blastocysts is inhibition of polyamine synthesis. Partial reversal of the effects of these inhibitors was obtained by supplying exogenous polyamines in the medium. However, since spermine and spermidine were toxic at higher concentrations, complete reversal could not be attempted with these two polyamines.

Polyamines themselves are probably not toxic to mouse blastocysts; the oxidation products of polyamines, produced by an amine oxidase in fetal calf serum (Byrd, Jacobs \& Amoss, 1977; Allen, 
Smith, Hussain, Thomas \& Gaugas, 1979; Bachrach, Menashe, Faber, Desser \& Seiler, 1981), are most likely responsible for the demise of these embryos. Like lymphocytes (Bachrach et al., 1981), the cells of the blastocyst appear to be particularly susceptible to the inhibitory and/or toxic effects of oxidized polyamines. Spermine and spermidine were less toxic when MGBG was in the medium (Table 2) probably because MGBG is also an inhibitor of polyamine oxidase (Heby, 1981). In addition, inhibition of polyamine oxidation by MGBG probably helped prevent destruction of polyamines before they could be taken up by embryonic cells. Alexandre (1979) observed that $50 \mu \mathrm{M}$-spermine and spermidine are toxic to cleavage-stage embryos in medium containing bovine serum albumin, and commercially available preparations of this protein are contaminated with polyamine oxidase (Tabor \& Tabor, 1972).

Polyamines were able to partly overcome inhibition of growth by MGBG (Table 4), suggesting that this inhibitor slows development by decreasing polyamine content and/or synthesis in mouse blastocysts. Moreover, methylornithine appears to have a primary effect on polyamine synthesis in diapausing blastocysts since putrescine $\left(10^{-3} \mathrm{M}\right)$ completely reversed the inhibitory effects of methylornithine on these embryos (Table 5). While putrescine stimulated the onset of trophoblastic outgrowth in the absence of methylornithine, this amine stimulated the production of larger outgrowths only in the presence of methylornithine. These results suggest that methylornithine inhibits growth of diapausing blastocysts by interrupting polyamine synthesis.

The results of this study indicate that polyamine synthesis may be an integral part of the activation process of diapausing blastocysts, which leads to attachment of the embryos to the culture dish and trophoblastic outgrowth in vitro. A combination of inhibitors known to slow polyamine synthesis in other systems (Heby, 1981) completely prevented the onset of trophoblastic outgrowth by diapausing embryos (Table 1). Furthermore, blastocysts, removed from medium containing these inhibitors and cultured in fresh medium, formed outgrowths at about the same time as would have been expected had they just been obtained from the uterus (Text-fig. 2). This result suggests that at least some aspect of metabolism, required before attachment and outgrowth can occur, has not taken place in the presence of the inhibitors of polyamine synthesis. Further studies are planned (a) to determine which aspects of metabolism are affected by inhibitors of polyamine synthesis (e.g. DNA, RNA and/or protein synthesis) and (b) to try to verify the hypothesis that polyamines are needed for activation and growth of diapausing blastocysts, by measuring changes in polyamine levels in these embryos after activation in utero with steroid hormones or after in-vitro incubation in the absence or presence of methylornithine and MGBG.

We thank Dr Wells Farnsworth, Dr David Mann, Dr Daniel Richardson, Ms Larriette Thompson, Mr Howard Wasserlauf and Ms Carol Williams for help in preparing this manuscript. Supported by the Chicago College of Osteopathic Medicine.

\section{References}

Alexandre, H. (1979) The utilization of an inhibitor of spermidine and spermine synthesis as a tool for the study of the determination of cavitation in the preimplantation mouse embryo. J. Embryol. exp. Morph. 53, 145-162.

Allen, J.C., Smith, C.J., Hussain, J., Thomas, J.M. \& Gaugas, J.M. (1979) Inhibition of lymphocyte proliferation by polyamines requires ruminant-plasma polyamine oxidase. Eur. J. Biochem. 102, 153158.

Bachrach, U., Menashe, M., Faber, J., Desser, H. \& Seiler, N. (1981) Polyamine biosynthesis and metabolism in transformed human lymphocytes. Adv. Polyamine Res. 3, 259-274.
Byrd, W.J., Jacobs, D.M. \& Amoss, M.S. (1977) Synthetic polyamines added to cultures containing bovine sera reversibly inhibit in vitro parameters of immunity. Nature, Lond. 267, 621-623.

Fowler, R.E. \& Edwards, R.G. (1957) Induction of superovulation and pregnancy in mature mice by gonadotrophins. J. Endocr. 15, 374-384.

Gwatkin, R.B.L. (1966) Amino acid requirements for attachment and outgrowth of mouse blastocysts in vitro. J. cell. Physiol. 68, 335-344.

Heby, O. (1981) Role of polyamines in the control of cell proliferation and differentiation. Differentiation 19 , $1-20$.

Kramer, C.Y. (1956) Extension of multiple range tests to 
group means with unequal numbers of replications. Biometrics 12, 307-311.

McLaren, A. (1973) Blastocyst activation. In Regulation of Mammalian Reproduction, pp. 321-328. Eds S. J. Segal, R. Crozies, P. A. Corfman \& P. G. Condliffe. Thomas, Springfield.

Naeslund, G. (1979) The effect of glucose-, arginine- and leucine-deprivation on mouse blastocyst outgrowth in vitro. Uppsala J. med. Sci. 84, 9-20.

Seidenfeld, J., Gray, J.W. \& Marton, L.J. (1981) Depletion of 9L-rat brain tumor cell polyamine content by treatment with DL-alpha-difluoromethylornithine inhibits proliferation and the $G_{1}$ to $S$ transition. Expl Cell Res. 131, 209-216.

Sherman, M.I. \& Barlow, P.W. (1972) Deoxyribonucleic acid content in delayed mouse blastocysts. $J$. Reprod. Fert. 29, 123-126.

Sherman, M.I. \& Wudl, L.R. (1976) The implanting mouse blastocyst. In The Cell Surface in Animal Embryogenesis and Development, pp. 81-125. Eds G. Poste \& G. L. Nicolson. Elsevier/North-Holland Biomedical Press, Amsterdam.

Spindle, A.I. \& Pedersen, R.A. (1973) Hatching, attachment and outgrowth of mouse blastocysts in vitro: fixed nitrogen requirements. J. exp. Zool. 186, 305318.

Sunkara, P.S. \& Rao, P.N. (1981) Differential cell cycle response of normal and transformed cells to polyamine limitation. Adv. Polyamine Res. 3, 347-356.

Tabor, H. \& Tabor, C.W. (1972) Biosynthesis and metabolism of 1,4-diaminobutane, spermidine, spermine and related amines. Adv. Enzymol. 36, 203-268.
Tabor, H. \& Tabor, C.W. (1976) 1,4-Diaminobutane (putrescine), spermidine and spermine. A. Rev. Biochem. 45, 285-306.

Van Blerkom, J.D., Chavez, D.J. \& Bell, H. (1979) Molecular and cellular aspects of facultative delayed implantation in the mouse. In Maternal Recognition of Pregnancy (Ciba Fdn Symp. No. 64), pp. 141-163. Excerpta Medica, Amsterdam.

Van Winkle, L.J. (1977) Low $\mathrm{Na}^{+}$concentration : a factor contributing to diminished uptake and incorporation of amino acids by diapausing mouse blastocysts? $J$. exp. Zool. 202, 275-281.

Van Winkle, L.J. (1981a) Activation of amino acid accumulation in delayed implantation mouse blastocysts. J. exp. Zool. 218, 239-246.

Van Winkle, L.J. (1981b) Chymotrypsin stimulated development of delayed implantation mouse blastocysts. Biochem. biophys. Res. Comm. 98, 562-568.

Van Winkle, L.J. \& Campione, A.L. (1982) Toxic effects of $\mathrm{Zn}^{++}$and $\mathrm{Cu}^{++}$on mouse blastocysts in vitro. Experientia 38, 354-356.

Viceps-Madore, D., Chen, K.Y., Tsou, H.-R. \& Canellakis, E.S. (1982) Studies on the role of protein synthesis and of sodium on the regulation of ornithine decarboxylase activity. Biochim. biophys. Acta 717, 305-315.

Williams-Ashman, H.G. \& Canellakis, Z.N. (1979) Polyamines in mammalian biology and medicine. Perspect. Biol. Med. 22, 421-453.

Woolf, D.M. (1968) Principles of Biometry. D. Van Nostrand, London.

Received 16 December 1982 